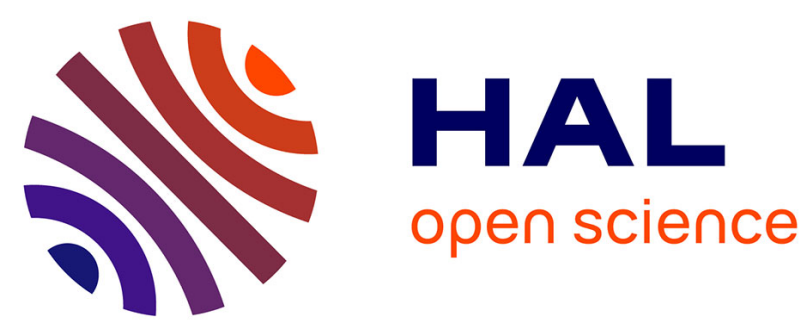

\title{
Reductions in use of hormone replacement therapy: effects on Swedish breast cancer incidence trends only seen after several years
}

Mats Lambe, Annette Wigertz, Marit Holmqvist, Jan Adolfsson, Carola Bardage, Tommy Fornander, Per Karlsson, Viveca Odlind, Ingemar Persson, Johan Ahlgren, et al.

\section{To cite this version:}

Mats Lambe, Annette Wigertz, Marit Holmqvist, Jan Adolfsson, Carola Bardage, et al.. Reductions in use of hormone replacement therapy: effects on Swedish breast cancer incidence trends only seen after several years. Breast Cancer Research and Treatment, 2009, 121 (3), pp.679-683. 10.1007/s10549009-0615-7 . hal-00612978

\section{HAL Id: hal-00612978 https://hal.science/hal-00612978}

Submitted on 2 Aug 2011

HAL is a multi-disciplinary open access archive for the deposit and dissemination of scientific research documents, whether they are published or not. The documents may come from teaching and research institutions in France or abroad, or from public or private research centers.
L'archive ouverte pluridisciplinaire HAL, est destinée au dépôt et à la diffusion de documents scientifiques de niveau recherche, publiés ou non, émanant des établissements d'enseignement et de recherche français ou étrangers, des laboratoires publics ou privés. 


\title{
Reductions in use of hormone replacement therapy: effects on Swedish breast cancer incidence trends only seen after several years
}

\author{
Mats Lambe $\cdot$ Annette Wigertz $\cdot$ Marit Holmqvist $\cdot$ Jan Adolfsson • \\ Carola Bardage $\cdot$ Tommy Fornander $\cdot$ Per Karlsson • Viveca Odlind • \\ Ingemar Persson • Johan Ahlgren $\cdot$ Leif Bergkvist
}

Received: 20 October 2009/ Accepted: 21 October 2009/Published online: 6 November 2009

(C) Springer Science+Business Media, LLC. 2009

\begin{abstract}
Studies from Western countries have found evidence of a recent decline in breast cancer incidence rates in postmenopausal women, findings which have been hypothesized to reflect a reduced use of hormonal replacement therapy (HRT). We examined breast cancer incidence trends in Sweden between 1997 and 2007, a period characterized by a drop in the use of HRT. Incidence trends were assessed using data from three
\end{abstract}

M. Lambe ( $\square)$

Department of Medical Epidemiology and Biostatistics,

Karolinska Institutet, PO Box 281, 17177 Stockholm, Sweden

e-mail: Mats.Lambe@ki.se

M. Lambe · A. Wigertz $\cdot$ M. Holmqvist

Regional Oncologic Centre, Uppsala, Sweden

A. Wigertz · J. Adolfsson

Oncologic Centre Stockholm and Gotland, Karolinska

University Hospital, Stockholm, Sweden

C. Bardage $\cdot$ V. Odlind · I. Persson

Medical Product Agency, Uppsala, Sweden

T. Fornander

Department of Oncology and Pathology, Karolinska Institutet,

Stockholm, Sweden

P. Karlsson

Department of Oncology, Sahlgrenska University Hospital, Gothenburg, Sweden

J. Ahlgren

Department of Oncology and Centre for Research and Development, Uppsala University, Gävle Hospital, Gävle, Sweden

L. Bergkvist

Department of Surgery and Centre for Clinical Research,

Uppsala University, Central Hospital, Västerås, Sweden population-based Regional Clinical Registries on breast cancer covering $2 / 3$ of the Swedish population. Information on HRT sales was obtained from national pharmacy data. The prevalence of HRT use in age group 50-59 years decreased from a peak of $36 \%$ in 1999 to $27 \%$ in 2002 and further to $9 \%$ in 2007 . Incidence rates of breast cancer in women 50 years and older increased between 1997 and 2003. A significant decrease in incidence between 2003 and 2007 was confined to women 50-59 years of age, the group in which the prevalence of HRT use has been highest and the decrease in use most pronounced. As opposed to the immediate effects reported from the United States and other regions, there was a time lag between the drop in HRT use and clear reductions in breast cancer incidence. This may reflect between country differences with regard to types of HRT used, and the rate, magnitude and pattern of change in use. The present findings give further support to the notion that HRT use is a driver of breast cancer incidence trends on the population level.

Keywords Breast cancer - Incidence - Trends · Hormone replacement therapy $\cdot$ Sweden

\section{Introduction}

Following a continuous increase in breast cancer incidence rates since the early 1980s, studies from several Western countries have found evidence of recent sharp decreases in postmenopausal women. In an analysis based on data from nine US cancer registries, Ravdin et al. reported a $7 \%$ overall decrease in incidence between 2002 and 2003 in women older than 50 years of age and particularly for estrogen receptor positive tumors [1]. Subsequent studies from the US, Canada, Australia, France, Switzerland, 
Germany, Great Britain, Belgium, and the Nordic countries have also reported reductions in breast cancer incidence [2-14]. These changes have been hypothesized to be a result of a dramatic decline in the use of hormone replacement therapy (HRT) following the 2002 release of the report from the Women's Health Initiative (WHI) hormone trial [15]. However, it remains unclear whether a reduced use of HRT represents the main and only cause behind the reversal of breast cancer incidence trends. In the US, earlier increases in breast cancer incidence have primarily been discussed in terms of higher rates of detection because of rising mammography rates [16]. Also, the recent downward trend have by some authors been suggested to reflect saturation in mammography screening [17]. However, based on results from a mammography screening population other investigators have argued that stable rates of ductal carcinoma in situ disease support the notion of an important role of changes in HRT use [6].

Sweden has a high incidence of breast cancer, and a historically relatively high prevalence of HRT use. Using data from three population-based Regional Clinical Quality Registers on breast cancer, we examined in detail incidence trends in Sweden between 1997 and 2007, a period characterized by a drop in the use of HRT.

\section{Materials and methods}

Use of hormone replacement therapy

Aggregated information on annual sales of HRT to women aged 50-69 years was obtained from the drug sales database of The Swedish National Corporation of Pharmacies in which all drugs are classified by the Anatomical Therapeutic Chemical (ATC) classification system. Sales figures over time for the group G03C (estrogens) and G03D (progestogens) and G03F (preparations with fixed combinations of estrogen and progestogens) were assessed. In the estrogen group, only medium-potency estrogens were included. Data were collected in the form of defined daily dosages (DDDs) per 1,000 women in age groups, i.e., the number of average recommended maintenance doses per day for a drug for its main indication in adults relative to the number of women in the respective age group.

\section{Breast cancer incidence}

Incidence trends between 1997 and 2007 were estimated for women in three administrative health care regions in Sweden, covering more than 5 million inhabitants corresponding to $62 \%$ of the Swedish population (UppsalaÖrebro, Västra Götaland, and Stockholm-Gotland). Data on incident cases of breast cancer (invasive and in situ) were retrieved from Regional Clinical Quality Registries on breast cancer that include information on date of diagnosis, tumor stage, tumor characteristics, and primary treatment on all newly diagnosed breast cancer patients. The Regional Quality Registers are validated against the national Swedish Cancer Register and all have a completeness exceeding $96 \%$.

Statistical analysis

Breast cancer incidence rates were calculated based on the number of cases for each 5 year age group, divided by the corresponding mean population per 100,000. Age specific incidence rates were adjusted to the age distribution of the Swedish population on January 1, 2000.

Breast cancer incidence data are presented with estimates per 100,000 women by year of diagnosis (19972007). In order to test incidence trends, a regression model was used where the breakpoint was set to 2003. Temporal patterns of HRT use from pharmacy sales data are presented as DDD/1,000 women by calendar year.

\section{Results}

Following a sharp increase in sales beginning in the late 1980s, HRT use peaked in 1999 (Fig. 1) with an estimated prevalence in age group 50-69 years of 27\% compared to $23 \%$ in 2002 and $9 \%$ in 2007. The corresponding estimates in women aged 50-59 were 36,27 , and $9 \%$ and in women aged 60-69 were 19, 19, and 9\%. Thus, in the age group 50-59 where HRT use was most common, the prevalence declined by $25 \%$ between 1999 and 2002, and by more than $70 \%$ between 1999 and 2007.

Among women 50-59 years of age and prescribed HRT in 1999, 59\% used fixed combinations of estrogen and progestogens, either combined continuously or sequentially, and $41 \%$ were given estrogen, either unopposed or together with a separate prescription of a progestogen. The estrogen component in the majority of HRT prescriptions in Sweden is estradiol, whereas a small proportion used to be conjugated estrogens. Since 2007 conjugated estrogens are no longer marketed in Sweden.

Among women using fixed combinations the use of combined continuous preparations increased between 2000 and 2005. The progestogen component used in fixed combinations, both in continuous and sequential preparations was most often norethisterone acetate (NETA) during the same time period, but medroxyprogesterone acetate preparations (MPA) were also used (Table 1).

The incidence of invasive breast cancer increased in all age groups in women 50 years and older between 1997 and 2003. A statistically significant decrease in incidence 
Fig. 1 HRT pharmacy sales data for women 50-59 years of age in Sweden

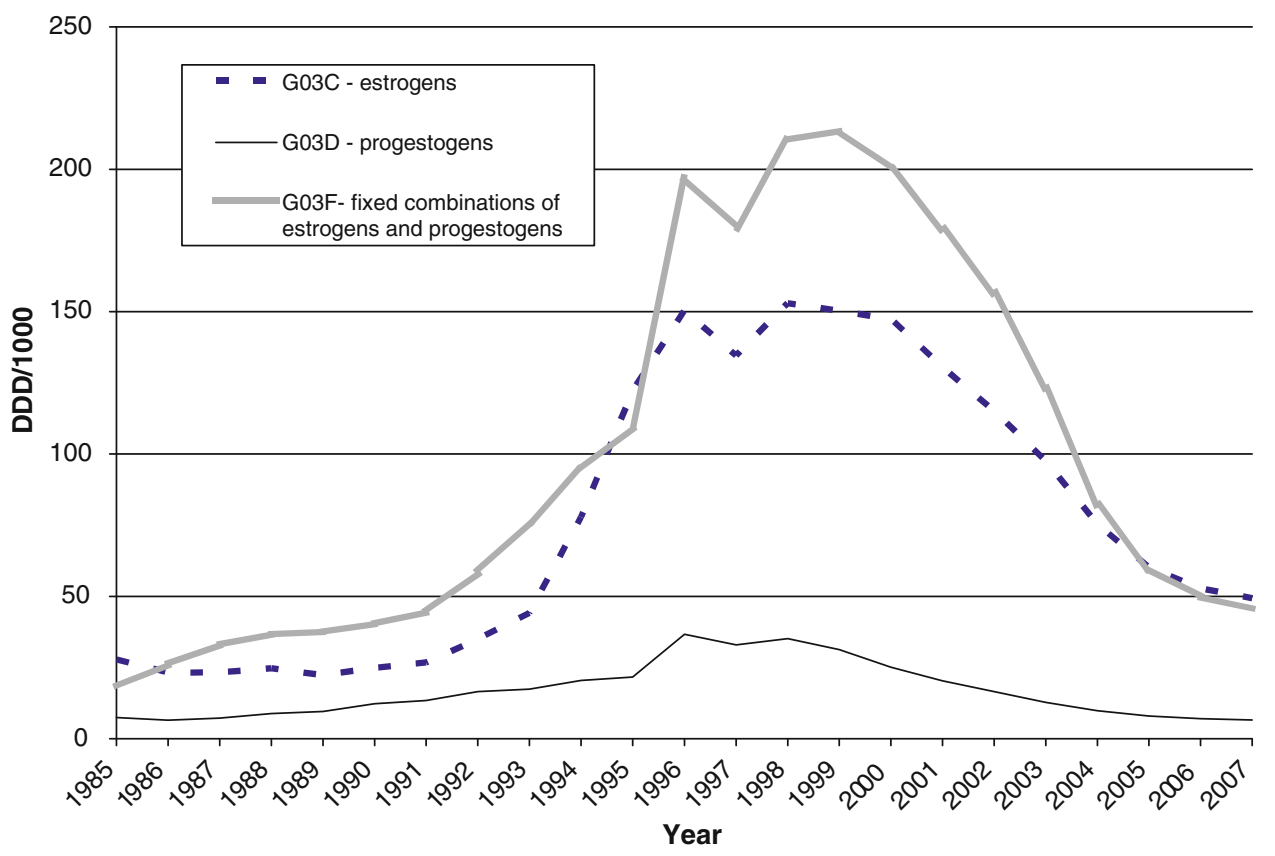

Table 1 Distribution (\%) of combined continuous and sequential products during 2000 and 2005 among women 50-59 years using fixed combinations and the proportion (\%) of norethisterone acetate (NETA) and medroxyprogesterone acetate (MPA) as the progestogen component in fixed continuous and sequential combinations

\begin{tabular}{lllll}
\hline & 2000 & NETA/MPA & 2005 & NETA/MPA \\
\hline Combined continuous & 60 & $73 / 27$ & 68 & $59 / 39$ \\
Combined sequential & 40 & $70 / 26$ & 32 & $78 / 20$ \\
\hline
\end{tabular}

between 2003 and 2007 was confined to women 5059 years of age $(P<0.05)$ and corresponded to a reduction of $4.5 \%$ per year (Figs. 2, 3). Among women $50-59$ years the incidence pattern for $\mathrm{ER}^{+}$(estrogen receptor positive) tumors was similar to that of all invasive tumors. No significant changes in incidence rates of lobular cancers or of in situ cancers were observed during the period under study (Fig. 3).

Among all invasive tumors in women aged 50-59 years, $72 \%$ were $\mathrm{ER}^{+}$(estrogen receptor positive), $17 \%$ were $\mathrm{ER}^{-}$(estrogen receptor negative), and $11 \%$ had an unknown estrogen receptor status. Ductal and lobular type cancers represented 69 and 15\%, respectively, of all invasive cases.

\section{Discussion}

Multiple factors may influence breast cancer incidence trends including temporal changes in reproductive patterns, lifestyle factors associated with affluence, use of

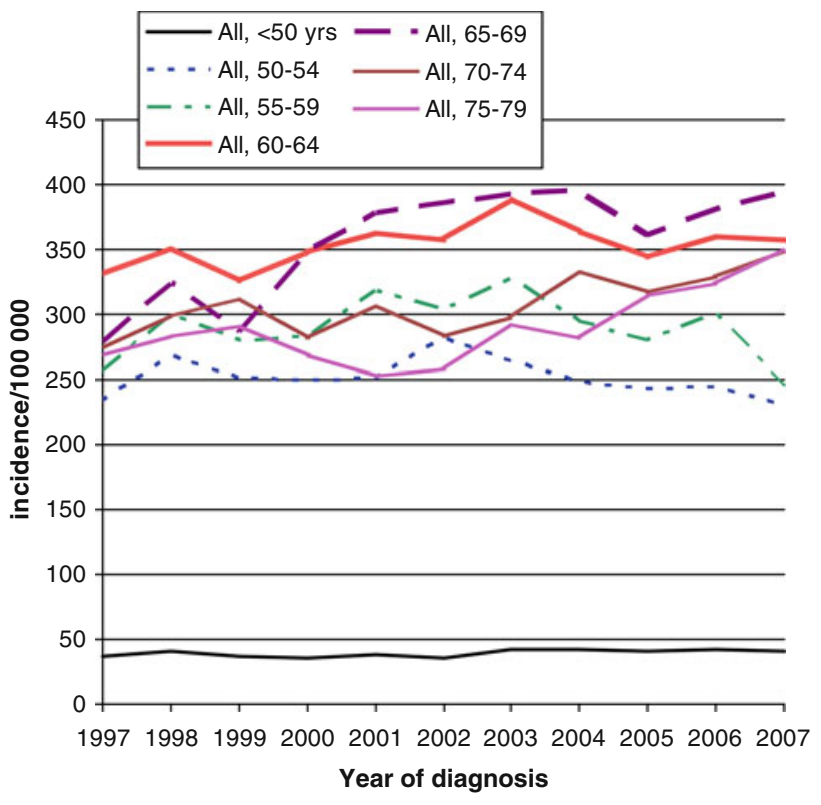

Fig. 2 Invasive breast cancer incidence in women in StockholmGotland, Västra Götaland, and Uppsala-Örebro region in Sweden per year in 5-year age groups

mammography, and exogenous female sex hormones. Our population-based study showed a decrease in breast cancer incidence beginning in 2003 that was confined to women 50-59 years, the age group in which HRT use has been most prevalent and the decrease in use has been largest both in relative and absolute terms. With a time lag of 4-5 years between the start of the fall of HRT use and a detectable decline in incidence, our findings are in line with the observation that HRT associated increased risks of 


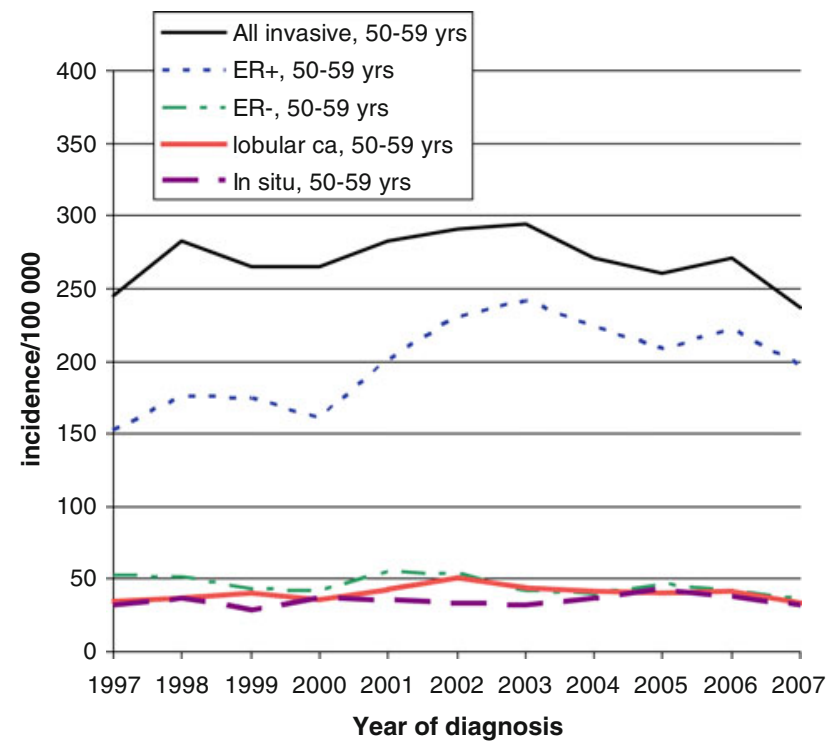

Fig. 3 Breast cancer incidence in women 50-59 years of age for invasive cancer, ER-positive and ER-negative cancer, lobular and in situ cancer per year in Stockholm-Gotland, Västra Götaland, and Uppsala-Örebro region in Sweden

breast cancer disappear within a few years after discontinuation of use [18, 19]. In some, but not all, earlier reports the decrease in incidence was most pronounced for $\mathrm{ER}^{+}$-tumors $[1,4,6]$. In the present study, $\mathrm{ER}^{+}$-tumors represented 3/4 of all tumors in women 50-59 years of age with a decrease in incidence closely resembling temporal patterns for all cancers in this age group. Lobular cancers have also been postulated to be particularly sensitive to hormonal stimulation. While a few investigators have reported larger recent decreases in incidence for lobular cancers than for ductal cancers $[14,20]$, we found no evidence of a different incidence pattern for the small subgroup of lobular carcinomas available for analyses in the present study.

Saturation of mammography screening has been suggested to explain a slight decline in US breast cancer incidence observed in the years preceding the WHI report [4], and also that it played a role for the continued decrease up until 2004 [17]. Organized, invitational mammography service screening was introduced gradually in Sweden beginning in 1974, covered $85 \%$ of Swedish counties in 1992, and achieved full national coverage in 1997 [21]. While the age groups invited have varied between geographical regions and over time, the age group of particular interest in the present study (50-59 years) was included from the start in all programs with at least biennial invitations, and a steady state can be expected to have been reached well before year 2000. The incidence of in situ cancers can be seen as a measure of mammography saturation and utilization since this subtype most often is detected by mammography. During the period under study, the incidence rates of breast cancer in situ remained stable indicating no major changes in the use of mammography in Sweden. Thus, it appears unlikely that patterns of mammography use could explain our findings.

In Sweden, the most commonly used HRT therapies have been continuous or sequential combinations of estradiol and NETA or MPA (Fig. 1, Table 1). In the US conjugated estrogens have predominated. The WHI randomized placebo-controlled trial tested conjugated equine estrogens (CEE) in continuous combination with MPA [15]. Types of estrogen and progestogen and doses of the hormones, as well as routes of administration may be associated with different risks for the development of breast cancer. Combinations of estrogen and progestogen have been shown to confer a higher risk than estrogen-only treatment [22], and continuous combined HRTs has been suggested to confer a higher risk than sequentially administrated HRTs [23]. However, in a review of the risks and benefits of different HRT regimens it was concluded that the WHI findings based on CEE also are consistent with the risk profile for estradiol preparations [24].

Compared to the US and other countries, the decrease in breast cancer incidence in Sweden appears to have been more gradual and less rapid. This may reflect the differences in types of HRT used and that the prevalence of HRT use started to decline in 1999, several years before the release of the results of the WHI study. However, it should be noted that a slight decline in HRT use was detectable prior to 2002 also in the US [6]. The observation that breast cancer risk increases after only a few years of HRT exposure and that the risk declines within years of its discontinuation is compatible with HRT acting through growth stimulation of preexisting premalignant breast epithelial cells. Somewhat later decline in breast cancer incidence in Sweden compared with the US may reflect not only differential growth promoting effects of different HRT regimens, but possibly also differences in the proportions of short- versus long-term users discontinuing their treatment.

Strengths of the present study included the availability of high quality detailed population-based clinical data to assess incidence trends of breast cancer by subtypes. Like most earlier post-WHI reports on breast cancer incidence trends, individual level data on mammography use, or hormonal therapy were unavailable. Our sales-based estimates of time trends of prevalence of HRT use were in line with results from earlier Swedish studies that have assessed use from questionnaire data $[25,26]$.

In conclusion, our finding of a decreasing breast cancer incidence trend in the age group previously most exposed to HRT is unlikely to be explained by changes in mammography utilization, registration routines in the Clinical Quality Registries on breast cancer, or shifts in established risk factors. If anything, an increase in the prevalence of 
postmenopausal obesity and changes in reproductive risk factors (e.g., earlier menarche and postponement of child bearing) would drive incidence trends in the opposite direction. Taken together, our results indicate that HRT use has been a driver of population rates of breast cancer also in Sweden with changes in incidence patterns reflecting country specific particulars of use.

Acknowledgments The study was supported by grants from the Swedish Council for Working life and Social research (\#2007-214), Regional Research Council Uppsala-Örebro (\#10316), and ALF Uppsala University Hospital (\#43159).

\section{References}

1. Ravdin PM, Cronin KA, Howlader N, Berg CD, Chlebowski RT, Feuer EJ, Edwards BK, Berry DA (2007) The decrease in breastcancer incidence in 2003 in the United States. N Engl J Med 356:1670-1674

2. Clarke CA, Glaser SL, Uratsu CS, Selby JV, Kushi LH, Herrinton LJ (2006) Recent declines in hormone therapy utilization and breast cancer incidence: clinical and population-based evidence. $\mathrm{J}$ Clin Oncol 24:e49-e50

3. Glass AG, Lacey JV Jr, Carreon JD, Hoover RN (2007) Breast cancer incidence, 1980-2006: combined roles of menopausal hormone therapy, screening mammography, and estrogen receptor status. J Natl Cancer Inst 99:1152-1161

4. Jemal A, Ward E, Thun MJ (2007) Recent trends in breast cancer incidence rates by age and tumor characteristics among U.S. women. Breast Cancer Res 9:R28

5. Keegan TH, Chang ET, John EM, Horn-Ross PL, Wrensch MR, Glaser SL, Clarke CA (2007) Recent changes in breast cancer incidence and risk factor prevalence in San Francisco Bay area and California women: 1988 to 2004. Breast Cancer Res 9:R62

6. Kerlikowske K, Miglioretti DL, Buist DS, Walker R, Carney PA (2007) Declines in invasive breast cancer and use of postmenopausal hormone therapy in a screening mammography population. J Natl Cancer Inst 99:1335-1339

7. Robbins AS, Clarke CA (2007) Regional changes in hormone therapy use and breast cancer incidence in California from 2001 to 2004. J Clin Oncol 25:3437-3439

8. Canfell K, Banks E, Moa AM, Beral V (2008) Decrease in breast cancer incidence following a rapid fall in use of hormone replacement therapy in Australia. Med J Aust 188:641-644

9. Hemminki E, Kyyronen P, Pukkala E (2008) Postmenopausal hormone drugs and breast and colon cancer: nordic countries 1995-2005. Maturitas 61:299-304

10. Katalinic A, Rawal R (2008) Decline in breast cancer incidence after decrease in utilisation of hormone replacement therapy. Breast Cancer Res Treat 107:427-430

11. Bouchardy C, Usel M, Verkooijen HM, Fioretta G, Benhamou S, Neyroud-Caspar I, Schaffar R, Vlastos G, Wespi Y, Schäfer P, Rapiti E (2009) Changing pattern of age-specific breast cancer incidence in the Swiss canton of Geneva. Breast Cancer Res Treat. doi:10.1007/s10549-009-0478-y
12. Parkin DM (2009) Is the recent fall in incidence of post-menopausal breast cancer in UK related to changes in use of hormone replacement therapy? Eur J Cancer 45:1649-1653

13. Seradour B, Allemand H, Weill A, Ricordeau P (2009) Changes by age in breast cancer incidence, mammography screening and hormone therapy use in France from 2000 to 2006. Bull Cancer 96:E1-E6

14. Vankrunkelsven P, Kellen E, Lousbergh D, Cloes E, Op de Beeck L, Faes C, Bruckers L, Mertens R, Coebergh JW, Van Leeuwen FE, Buntinx F (2009) Reduction in hormone replacement therapy use and declining breast cancer incidence in the Belgian province of Limburg. Breast Cancer Res Treat 118:425-432

15. Rossouw JE, Anderson GL, Prentice RL, LaCroix AZ, Kooperberg C, Stefanick ML, Jackson RD, Beresford SA, Howard BV, Johnson KC, Kotchen JM, Ockene J (2002) Risks and benefits of estrogen plus progestin in healthy postmenopausal women: principal results from the Women's Health Initiative randomized controlled trial. JAMA 288:321-333

16. Krieger N (2008) Hormone therapy and the rise and perhaps fall of US breast cancer incidence rates: critical reflections. Int $\mathrm{J}$ Epidemiol 37:627-637

17. Li CI, Daling JR (2007) Changes in breast cancer incidence rates in the United States by histologic subtype and race/ethnicity, 1995 to 2004. Cancer Epidemiol Biomarkers Prev 16:2773-2780

18. Collaborative Group on Hormonal Factors in Breast Cancer (1997) Breast cancer and hormone replacement therapy: collaborative reanalysis of data from 51 epidemiological studies of 52, 705 women with breast cancer and 108, 411 women without breast cancer. Lancet 350:1047-1059

19. Chlebowski RT, Kuller LH, Prentice RL, Stefanick ML, Manson JE, Gass M, Aragaki AK, Ockene JK, Lane DS, Sarto GE, Rajkovic A, Schenken R, Hendrix SL, Ravdin PM, Rohan TE, Yasmeen S, Anderson G (2009) Breast cancer after use of estrogen plus progestin in postmenopausal women. N Engl J Med 360:573-587

20. Eheman CR, Shaw KM, Ryerson AB, Miller JW, Ajani UA, White MC (2009) The changing incidence of in situ and invasive ductal and lobular breast carcinomas: United States, 1999-2004. Cancer Epidemiol Biomarkers Prev 18:1763-1769

21. Olsson S, Andersson I, Karlberg I, Bjurstam N, Frodis E, Hakansson S (2000) Implementation of service screening with mammography in Sweden: from pilot study to nationwide programme. J Med Screen 7:14-18

22. Beral V (2003) Breast cancer and hormone-replacement therapy in the Million Women Study. Lancet 362:419-427

23. Olsson HL, Ingvar C, Bladstrom A (2003) Hormone replacement therapy containing progestins and given continuously increases breast carcinoma risk in Sweden. Cancer 97:1387-1392

24. Warren MP (2004) A comparative review of the risks and benefits of hormone replacement therapy regimens. Am J Obstet Gynecol 190:1141-1167

25. Hoffmann M, Hammar M, Kjellgren KI, Lindh-Astrand L, Brynhildsen J (2005) Changes in women's attitudes towards and use of hormone therapy after HERS and WHI. Maturitas 52:11-17

26. Thunell L, Stadberg E, Milsom I, Mattsson LA (2005) Changes in attitudes, knowledge and hormone replacement therapy use: a comparative study in two random samples with 6-year interval. Acta Obstet Gynecol Scand 84:395-401 